\title{
Differential potency of vitamin D3, folic acid and memantine in protecting against neurobehavioral alterations of scopolamine induced Alzheimer's model in rats
}

\author{
Abeer A. Eldeeb ${ }^{1}$, Amira E. Fathy ${ }^{2}$, Salwa A. Elgendy ${ }^{1 *}$
}

${ }^{1}$ Department of Pharmacology, ${ }^{2}$ Department of Histology and Cell Biology, Faculty of Medicine, Benha University, Benha, Egypt

Received: 18 January 2021

Revised: 04 April 2021

Accepted: 05 April 2021

\section{*Correspondence:}

Dr. Salwa A. Elgendy,

Email: salwaeg@yahoo.com

Copyright: $\odot$ the author(s), publisher and licensee Medip Academy. This is an open-access article distributed under the terms of the Creative Commons Attribution Non-Commercial License, which permits unrestricted non-commercial use, distribution, and reproduction in any medium, provided the original work is properly cited.

\section{ABSTRACT}

Background: Alzheimer disease is the cause of $60 \%$ to $70 \%$ of cases of dementia in elderly people, it is a chronic neurodegenerative disease that usually starts slowly and worsens over time. AD is characterized by the presence of senile plaques enriched with insoluble aggregate of beta-amyloid, neurofibrillary tangles and cholinergic neuronal degeneration in the brain tissue, leading to neural dysfunction, neuroinflammation, and critical pathological perturbations.

Methods: Thirty-six males were classified into control group, Alzheimer-induced model (scopolamine $2.5 \mathrm{mg} / \mathrm{kg} \mathrm{IP}$ once daily for 21 days). Folic acid-treated group ( $4 \mathrm{mg} / \mathrm{kg}$, IP) once daily for 21 days with scopolamine. Vitamin D3treated group (42 IU/kg, SC) once daily for 21 days with scopolamine. Vitamin D3 and folic acid-treated group (vitamin D3; $42 \mathrm{IU} / \mathrm{kg}$, SC and folic acid; $4 \mathrm{mg} / \mathrm{kg}$, IP) once daily with scopolamine for 21 days. Memantine-treated group $(20 \mathrm{mg} / \mathrm{kg} \mathrm{IP})$ once daily with scopolamine for 21 days.

Results: Induction of Alzheimer's showed significant decrease in brain tissue levels of BDNF, Ach, glutathione reductase and significant increase in amyloid peptide 1-42 level with significant memory impairment, significant increase of initial acquisition latency, first ${ }^{t}$ retention latency and second retention latency. While administration of folic acid, vitamin D3, memantine separately or in combination resulted insignificant increase of brain tissue levels of BDNF, Ach, glutathione reductase with significant reduction of amyloid peptide 1-42 level with significant memory improvement (significant decrease IAL, first RL and second RL). Also showed improvement of histopathological changes occurred in the brain.

Conclusions: Data obtained in the present study revealed that treatment of experimentally induced alzheimer rats with folic acid or vitamin $\mathrm{D}_{3}$ or memantine separately or combined group (folic acid+vitamin $\mathrm{D}_{3}$ ) resulted in significant increase of brain tissue levels of BDNF, acetyl choline, glutathione reductase with significant reduction of amyloid peptide 1-42 level with significant decrease of IAL, first RL and second RL to reach the platform with improvement of histopathological changes occurred in the brain. But combined and memantine-treated groups resulted in more significant improvement than other treated groups.

Keywords: Alzheimer, Vitamin D3, Folic acid, Memantine, BDNF, Glutathione reductase, Cognitive function

\section{INTRODUCTION}

Memory is one of the main roles of the brain, it is vital for survival of organisms by which they are able to record their experiences and use this information to adapt their response to the environment. The gradual loss of memory and impaired cognitive functions are the major features of Alzheimer disease (AD). ${ }^{1}$ The global prevalence of 
dementia has been estimated to be as high as 24 million and is predicted to double every 20 years until at least 2040. As the population worldwide continues to age, the number of individuals at risk will also increase, particularly among the elderly. ${ }^{2}$ The most common early symptom of $\mathrm{AD}$ is difficulty in remembering recent events (short-term memory loss). By time, disorientation (including easily getting lost), mood swings, loss of motivation, not managing self-care and behavioral issues. As a person's condition declines, they often withdraw from family and society. Gradually, bodily functions are lost, ultimately leading to death. ${ }^{3}$ The main pathological features of AD include extracellular amyloid plaques deposition leading to intra-neuronal neurofibrillary tangles (NFTs) of hyper-phosphorylated microtubule associated tau protein, an inflammatory reaction and ultimately cause neuronal death. ${ }^{4}$ Although the main etiology and mechanisms of neuronal cell loss in AD have not yet been definitively elucidated, the elevated oxidative stress and the inflammatory reactions are considered important mediators of neuronal damage in AD. ${ }^{5}$

Throughout the world, about one billion of vitamin Ddeficient people suffered from $\mathrm{AD}$ with a prevalence of approximately $70-90 \% .^{6}$ Vitamin D has been found to pose a neuroprotective effect through its nuclear hormone receptor (VDRs) which present in all regions essential to cognition such as neurons and glial cells of the hippocampus, cortex and sub-cortex. ${ }^{7}$ Binding of vitamin $\mathrm{D}$ on the VDRs triggers neuronal protection against $\mathrm{AD}$ degenerative processes, including anti-inflammatory action, antioxidant effect, control of calcium homeostasis by regulating the concentration of intracellular calcium in hippocampal neurons, anti-atrophic effect by regulating neurotrophic agents, attenuation of $\mathrm{A} B-42$ peptide accumulation by stimulating the phagocytosis of $A B$ peptide together with enhancing brain-to-blood $A B$ efflux transport at the blood-brain barrier, and the prevention of acetylcholine defect by increasing the activity of choline acetyl transferase (thus the bioavailability of acetylcholine) in the brain. ${ }^{8}$ Vitamin $\mathrm{D}$ receptors are expressed throughout the brain, including areas involved in memory such as the hippocampus and dentate gyrus. Similarly, the enzyme that synthesizes the active form of vitamin $\mathrm{D}, 1 \alpha$-hydroxylase, is produced in several cerebral regions. ${ }^{9}$ The active form of vitamin $\mathrm{D}, 1,25$ dihydroxy-vitamin D3 (1,25-D3), regulates neurotrophin expression, such as nerve growth factor, neurotrophin, glial-derived neurotrophic factor and the survival, development, and function of neural cells. ${ }^{10}$ Folic acid is important for the activity of nervous system. It is essential for the production and maintenance of new cells, synthesis and maintenance of DNA synthesis of RNA and remethylation of homocysteine (homocysteine plays an important role in pathogenesis of AD). ${ }^{11}$ Studies have shown that folic acid is an effective antioxidant with free radical scavenging property that helps maintaining the integrity of neurons and improving the memory status during aging in AD. ${ }^{12}$ Folic Acid is an essential cofactor for the endogenous synthesis of CoQ10 and any deficiency in that would result in a deficiency in CoQ10. It has been demonstrated that CoQ10 acts as a radical scavenger and powerful antioxidant whose effects on improvement of cognitive functions has been shown. ${ }^{13} \mathrm{It}$ enhances the plasma concentrations of docosahexaenoic acid (DHA) and eicosapentaenoic acid (EPA). EPA, DHA, and arachidonic acid (AA) are of benefit in depression, dementia and Alzheimer's disease by upregulating gene expression concerned with neurogenesis, neurotransmission and connectivity, improving endothelial nitric oxide (eNO) generation, enhancing brain acetylcholine levels, and suppressing the production of pro-inflammatory cytokines. EPA, DHA, and AA also form precursors to anti-inflammatory compounds such as lipoxins, resolvins, and neuroprotectin D1 (NPD1) that protect neurons from the cytotoxic action of various noxious stimuli. ${ }^{14}$ Memantine used in treatment of AD by prevention overstimulation of the N-methyl-D-aspartate (NMDA) subtype of glutamate receptors to prevent calcium-induced excitotoxicity. ${ }^{15}$ It also acts as an inhibitor of a novel translation initiation mechanism, the internal ribosome entry site (IRES), so blocking the expression of APP and tau protein and thereby relieving the symptoms of AD. ${ }^{16}$ This study was designed to compare the protective effect of vitamin D3, folic acid and memantine on the progression of $\mathrm{AD}$ by assessment of cognitive performance through morris water maze test detect hippocampal tissue levels of BDNF, A $\beta$ 1-42, GR and Ach. Histopathological changes of brain tissue were observed.

\section{METHODS}

Current study was carried out on 36 adult male Wistar (albino) rats weighing 180-200 g. The animals were housed under standard laboratory conditions with natural light/dark cycle with free access to standard diet and water throughout the experimental period. The study was held from December 2020 to January 2020 for 21 day. The study was conducted at clinical pharmacology department, faculty of medicine, Benha University.

Normal control group, received saline only, untreated Alzheimer group received scopolamine $2.5 \mathrm{mg} / \mathrm{kg}$ IP once daily for 21 days. $^{17}$ Folic acid-treated group received folic acid (4 mg/kg, IP) once daily for 21 days. ${ }^{18}$ Vitamin $\mathrm{D}_{3}$ treated group received vitamin $\mathrm{D}_{3}$ (42 IU/kg SC) once daily for 21 days. ${ }^{19}$ Group $\mathrm{V}$ received vitamin $\mathrm{D}_{3}$ and folic acid-treated group: the rats of this group were given vitamin $\mathrm{D}_{3}(42 \mathrm{IU} / \mathrm{kg} \mathrm{SC})$ and folic acid (4 $\mathrm{mg} / \mathrm{kg}$, IP) once daily for 21 days. Group VI received memantine $(20 \mathrm{mg} / \mathrm{kg} \mathrm{IP})$ once daily for 21 days. ${ }^{20}$

\section{Statistical analysis}

Data were expressed as mean \pm standard deviation. They were tested for normality using Shapiro-Wilks test assuming normality at $\mathrm{p}>0.05$. Kruskal Wallis test was used to detect difference among the studied groups. 
Significant Kruskal Wallis test was followed by post hoc multiple comparisons using Bonferroni test to detect significant pairs. The accepted level of significance was at $\mathrm{p}<0.05$.

\section{RESULTS}

Effects of vitaminD, folic acid and memantine on progression of Alzheimer disease in rats after 3 weeks

Untreated Alzheimer group resulted in significant decrease in BDNF brain tissue (Table 1). while folic acid, vitamin $\mathrm{D}_{3}$, (folic acid+vitamin $\mathrm{D}_{3}$ ) and memantinetreated groups showed significant increase in comparison to untreated alzheimer group. Untreated Alzheimer group resulted in significant increase of brain tissue level of amyloid beta $1-42$, while folic acid, vitamin $D_{3}$, (folic acid+vitamin $D_{3}$ ) and memantine treated groups showed significant decrease of brain tissue level of amyloid beta 1-42 in comparison to untreated Alzheimer group (Table 1). Untreated Alzheimer group resulted in significant decrease of brain tissue level of acetyl-choline, while folic acid, vitamin $D_{3}$, (folic acid+vitamin $D_{3}$ ) and memantine-treated groups showed significant increase in comparison to untreated Alzheimer group (Table 1). Untreated Alzheimer group resulted in significant decrease of brain tissue level of glutathione reductase, while folicacid, vitamin $\mathrm{D}_{3}$, (folic acid+vitamin $\mathrm{D}_{3}$ ) and memantine-treated groups showed significant increase in comparison to untreated Alzheimer group (Table 1).

Table 1: Effects of folic acid and vitamin $D_{3}$ treatment separately and on combination and effect of memantine on brain tissue level of BDNF, amyloid beta 1-42, Ach and glutathione reductase levels in scoplolamine induced alzeheimer disease in rats at the end of the study.

\begin{tabular}{|c|c|c|c|c|}
\hline Groups & $\begin{array}{l}\text { BDNF } \\
(\mathrm{pg} / \mathrm{g} \text { tissue }) \\
(\mathrm{mean} \pm \mathrm{SD})\end{array}$ & $\begin{array}{l}\text { Amyloid beta } 1-42 \\
(\mathrm{pg} / \mathrm{g} \text { tissue) } \\
(\mathrm{mean} \pm \mathrm{SD})\end{array}$ & $\begin{array}{l}\text { Ach } \\
\text { (ng/g tissue) } \\
(\text { mean } \pm \text { SD) }\end{array}$ & $\begin{array}{l}\text { Glutathione reductase } \\
\text { (ng/g tissue) } \\
(\text { mean } \pm \text { SD) }\end{array}$ \\
\hline Control & $17.8 \pm 1.00$ & $3.7 \pm 0.60$ & $16.1 \pm 0.30$ & $3.39 \pm 0.34$ \\
\hline Untreated & $4.4 \pm 0.76^{\mathrm{a}}$ & $18.0 \pm 0.77^{\mathrm{a}}$ & $2.8 \pm 0.10^{\mathrm{a}}$ & $0.92 \pm 0.04^{\mathrm{a}}$ \\
\hline Folic acid treated & $9.5 \pm 0.18^{\mathrm{a}, \mathrm{b}}$ & $9.4 \pm 0.38^{\mathrm{a}, \mathrm{b}}$ & $10.4 \pm 0.37^{\mathrm{a}, \mathrm{b}}$ & $1.67 \pm 0.06^{\mathrm{a}, \mathrm{b}}$ \\
\hline Vitamin $D_{3}$ treated & $11.7 \pm 0.55^{\mathrm{a}, \mathrm{b}, \mathrm{c}}$ & $6.7 \pm 0.49^{\mathrm{a}, \mathrm{b}, \mathrm{c}}$ & $13.7 \pm 0.25^{\mathrm{a}, \mathrm{b}, \mathrm{c}}$ & $2.04 \pm 0.10^{\mathrm{a}, \mathrm{b}}$ \\
\hline Folic acid and vitamin $D_{3}$ & $16.6 \pm 0.47^{b, c, d}$ & $4.9 \pm 1.19^{b, c, d}$ & $15.5 \pm 0.72^{b, c, d}$ & $3.05 \pm 0.25^{b, c, d}$ \\
\hline Memantine treated & $17.3 \pm 0.80^{\mathrm{b}, \mathrm{c}, \mathrm{d}}$ & $4.5 \pm 0.31^{\mathrm{b}, \mathrm{c}, \mathrm{d}}$ & $15.7 \pm 0.63^{b, c, d}$ & $3.16 \pm 0.28^{b, c, d}$ \\
\hline
\end{tabular}

a, b, c, d Significant difference compared to control group, to untreated alzeheimer group, folic acid- treated group as well as compared to vitamin $\mathrm{D}_{3}$-treated alzeheimer group $(\mathrm{p}<0.05)$ respectively.

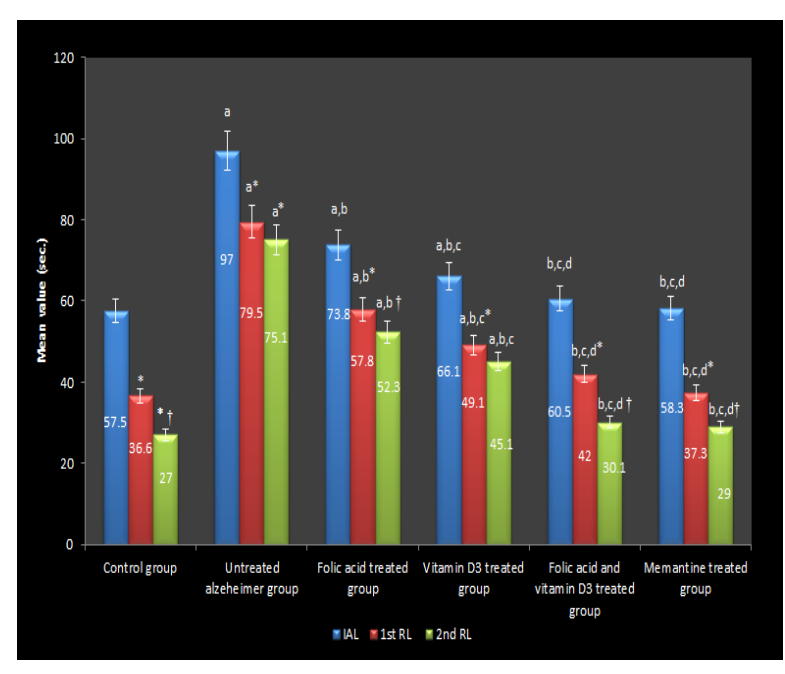

Figure 1: Cognitive performance through morriswater maze test among the studied groups. $\left({ }^{a, b, c, d}\right.$ Significant difference compared to control group, to untreated alzheimer group, folic acid- treated group as well as compared to vitamin $D_{3}$ treated alzheimer group $(\mathbf{p}<0.05)$ respectively. *Significant in comparison with IAL, $\uparrow$ Significant in comparison with first $\mathbf{R L}$ ).
Effects of folic acid, vitamin $\mathrm{D}_{3}$ and memantine on cognitive performance in Morris water maze test among the studied groups

Untreated Alzheimer group resulted in significant increase of initial acquisition latency (IAL)(day 13), first RL (day14) and second RL (day 21), while folic acid, vitamin $\mathrm{D}_{3}$, (folic acid+vitamin $\mathrm{D}_{3}$ ) and memantine showed significant decrease in comparison to untreated Alzheimer group.

\section{Histopathology}

Untreated AD group showing neuronal damage, amyloid deposition surrounded by clear halo, accumulation of glial cells around dystrophic neurons (gliosis) and formation of microglial nodule, vacuolated neuropil and congested blood vessels with perivascular edema in the cortex (Figure 4) with decrease pyramidal layer thickness in the hippocampus (Figure 5), all treated groups showing improvement of these changes, while memantine and combined groups more significant than others groups (Figure 6-9). 


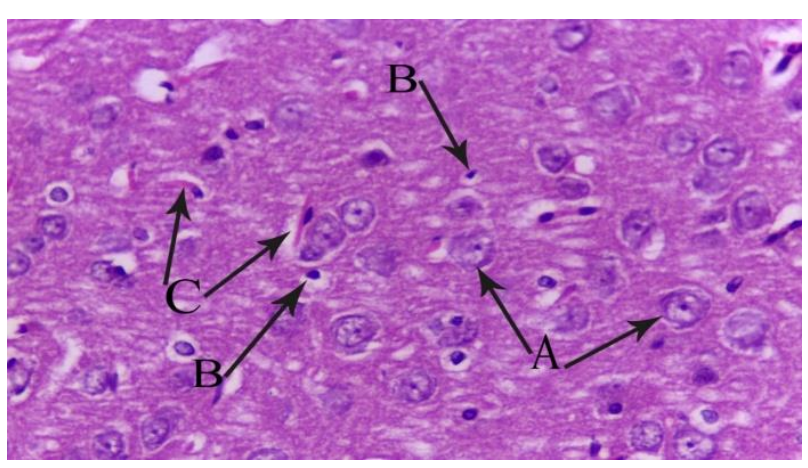

Figure 2: A photomicrograph of a cut section in the cerebral cortex of the brain of control rat (group I)

showing neurons that having huge nuclei with relatively pale stain, A) glial cells appeared with dense stain small nuclei and the condensed chromatin with no visible nucleoli, B) normal non-congested blood vessels, C) (H and $\mathrm{E}, 40 \mathrm{X})$.

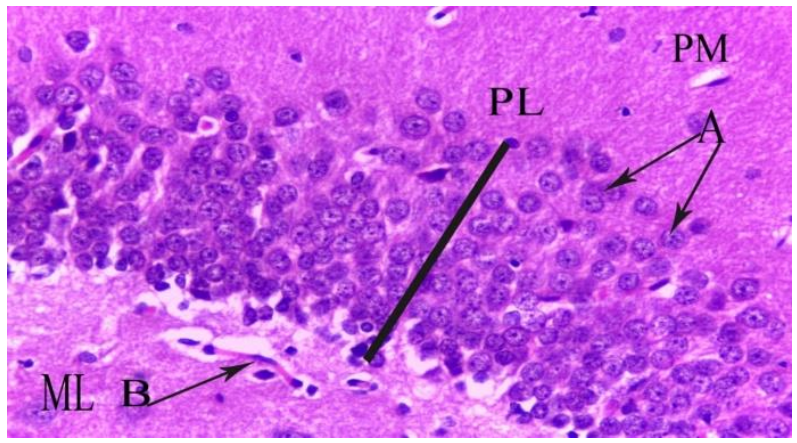

Figure 3: A photomicrograph of cut section in hippocampus of brain of control group showing; polymorphic (PM), pyramidal (PL) and molecular layers (ML) with normal hippocampal neurons, $A$ ) vessels exhibited regular arrangement with distinct edges and clear nuclei, B) (H and E, 40X).

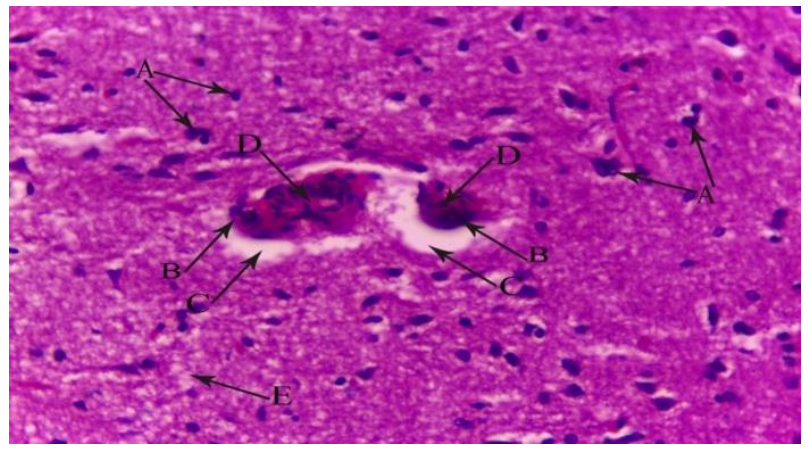

Figure 4: A photomicrograph of a cut section in the cerebral cortex of the brain of untreated alzheimer group (group II) showing neuronal damage, A) amyloid deposition, B) surrounded by clear halo, C) accumulation of glial cells around dystrophic neurons

(gliosis) and formation of microglial nodule, D) vacuolated neuropil, $\mathrm{E})$ congested blood vessels with perivascular edema, $\mathrm{F}$ ) ( $\mathrm{H}$ and $\mathrm{E}, 40 \mathrm{X})$.

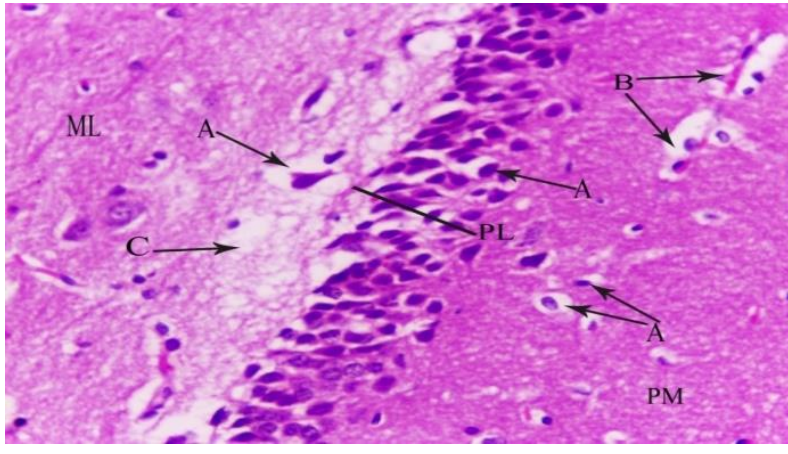

Figure 5: A photomicrograph of cut section in hippocampus of brain of untreated alzheimer group (group II) showing shrunken neuron cell size with

dense, hyperchromatic nuclei and each neuron acquired clear space around itself, A) fusion of two neuron together $B$ ) vacuolated neuropil, C) decrease pyramidal layer thickness (PL) (H and E, 40X).

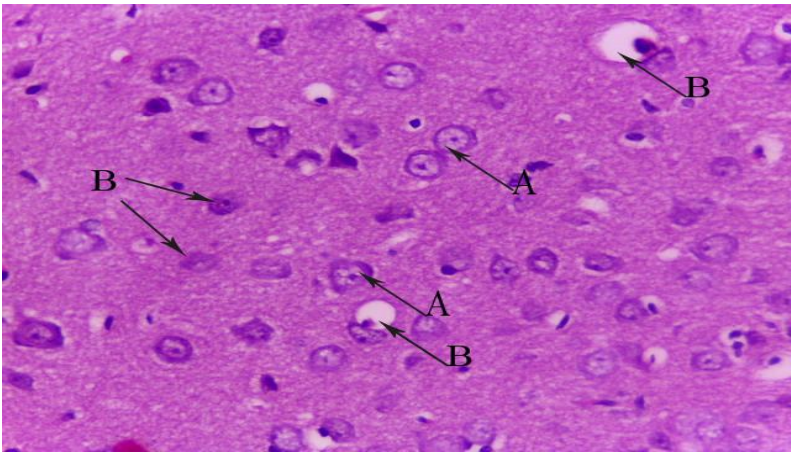

Figure 6: A photomicrograph of a cut section in the cerebral cortex of the brain of vitamin $D_{3}$ and folic acid-treated alzheimer group (group V) showing increase of normal neuronal cells, A) decrease neuronal shrinkage and damage some of them surrounded by clear halo space, B) (H and E, 40X).

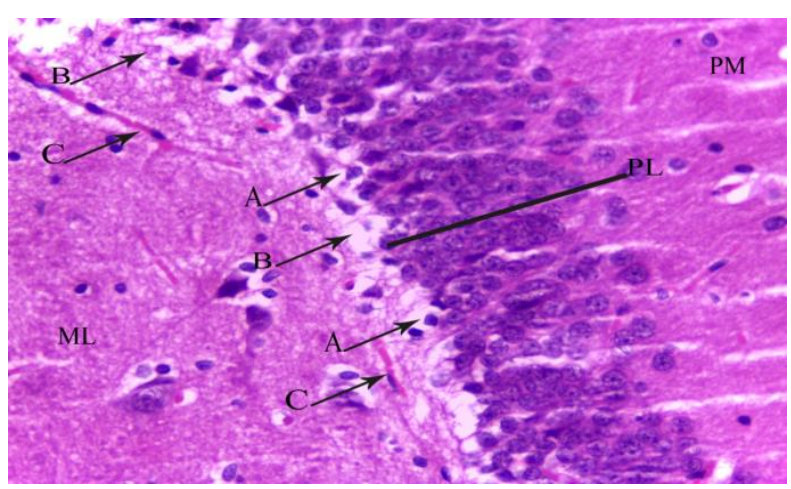

Figure 7: A photomicrograph of a cut section in the hippocampus of the brain of vitamin $\mathrm{D}_{3}$ and folic acidtreated Alzheimer group (group V) showing shrunken in the neuron cell size with dense, hyperchromatic nuclei, A) vacuolated neuropil, B) normal blood vessels, C) increase pyramidal layer thickness (PL) (H and $\mathrm{E}, \mathbf{4 0 X})$. 


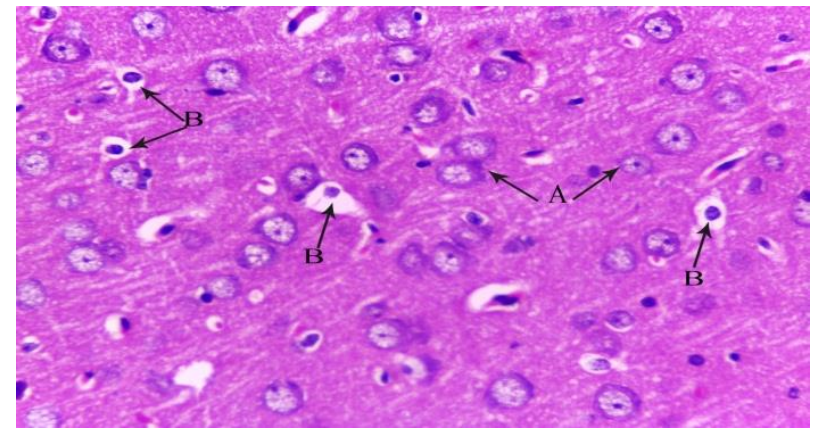

Figure 8: A photomicrograph of a cut section in the cerebral cortex of the brain of memantine-treated alzheimer group (group VI) showing increase of normal neuronal cells, A) decrease neuronal shrinkage and damage some of them surrounded by clear halo space, B) (H and E, 40X).

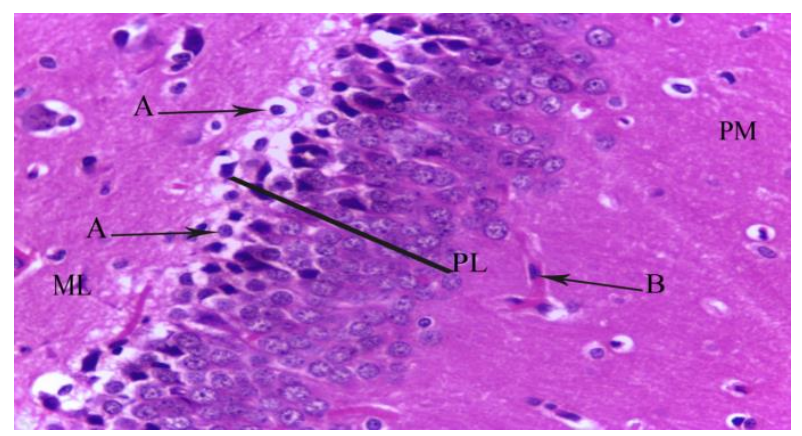

Figure 9: A photomicrograph of a cut section in the hippocampus of the brain of memantine treated

Alzheimer group (group VI) showing shrunken in neuron cell size with dense, hyperchromatic nuclei, A) normal blood vessels, B) increase pyramidal layer thickness (PL) (H and E, 40X).

\section{DISCUSSION}

The present study was designed to explore the beneficial protective effects of vitamin $\mathrm{D}_{3}$, folic acid and memantine on the progression of experimentally induced Alzheimerdisease in rats with scopolamine regarding to their effects on brain tissue levels of BDNF, amyloid beta 1-42, acetyl-choline, reduced glutathione, and assessment of cognitive function through morris-water maze test and histopathological changes of brain tissue.

The obtained results in the current work revealed that induction of $\mathrm{AD}$ by scopolamine resulted in significant decrease of brain tissue level of BDNF, acetyl-choline and reduced glutathione with significant increase in amyloid peptide 1-42 (A $\beta 1-42)$ level in brain tissue with significant memory impairment in Morris water maze test, as evident by significant increase of IAL, first tand second RL to reach the platform.

These results are in agreement with other study which revealed impairment of both learning and memory by scopolamine $(0.4 \mathrm{mg} / \mathrm{kg} \mathrm{IP})$ in rats. Scopolamine significantly shortened the second day latency compared to the control group. ${ }^{22}$ Bilateral injection of scopolamine $(0.6 \mathrm{mg} / \mathrm{kg})$ into the dorsal hippocampus (intra-CA1) of rats decreased memory consolidation and induced amnesia. $^{23}$ Scopolamine hydrobromide $(1,3,6,10$ $\mathrm{mg} / \mathrm{kg}$ ), was administered intraperitoneally to mice, caused dose and time dependent down regulation of the brain derived neurotrophic factor (BDNF) and glial fibrillary acidic protein (GFAP) expression. ${ }^{24}$ BDNF levels were significantly reduced in rat model of $\mathrm{AD}$ induced by intraperitoneal administration of aluminum chloride $(\mathrm{AlCl} 3)$, while other study reported that changes in serum level of BDNF might be contributing to shrinkage of the hippocampus that is associated with age related memory decline in late adulthood. ${ }^{25,26}$

In the present study, it was found that administration of folic acid, vitamin $\mathrm{D}_{3}$ and memantine for 3 weeks with scopolamine resulted in significant increase in brain tissue level of BDNF, acetyl-choline and reduced glutathione with significant decrease of amyloid peptide 1-42 (A $\beta 1-42)$, a significant memory improvement in Morris water maze test, as evident by the significant decrease of IAL, first and second RL to reach the platform. Improvement of histopathological changes occurred in the brain. But combined and memantinetreated groups resulted in more significant improvement than other treated groups.

These results are in line with evidence declaring that vitamin $\mathrm{D}_{3}$ stimulates expression of neurotrophic factors as nerve growth factor, glial neurotrophic factor and lowaffinity neurotrophin receptor in the brain neurons, and glial and schwann cells. ${ }^{9}$ However, chronic administration of vitamin D3 in rats decreased the hippocampus degenerative processes during aging. Furthermore, the development of $\mathrm{AD}$ is characterized by a significant reduction of nuclear vitamin $\mathrm{D}_{3}$ receptors. ${ }^{27}$ All these evidences suggest the importance of the antidegenerative activity of vitamin $\mathrm{D}_{3}$ as an underlying mechanism for its neuroprotective role. Vitamin $\mathrm{D}_{3}$ could upregulate neurotrophin factors, such as neurotrophin-3 (NT-3) and glial cell line derived neurotrophic factor (GDNF). It has been reported that the stimulation of neurotrophin production by vitamin $\mathrm{D}_{3}$ is correlated with its neuroprotective effect. Vitamin $\mathrm{D}_{3}$ was found to be a potent inducer of BDNF expression and it is contributed to the regulation of BDNF in vivo. ${ }^{28}$

The active form of vitamin $\mathrm{D}_{3}$ appears to enhance brain to blood $\mathrm{A} \beta$ efflux transport at the blood brain barrier (BBB) leading to enhancement of its cerebral clearance. ${ }^{29}$ Similarly, other reports documented that vitamin $\mathrm{D}_{3}$ supplementation modulated age-related increase in the hippocampal amyloid burden by controlling the proinflammatory state where the anti-inflammatory cytokine IL-10 increased while the pro-inflammatory cytokine IL$1 \beta$ decreased and increasing the activity of the amyloid degrading enzyme in cases of age-related cognitive decline in rats and suggested that vitamin $\mathrm{D}_{3}$ could be a 
useful therapeutic option to alleviate the effect of aging on cognitive function. ${ }^{19}$

Administration of vitamin $\mathrm{D}_{3}$ induce reduction in the formation of $A \beta$ oligomers seen in the aged rats by elevation $A \beta$-degrading enzyme neprilysin (NEP) in the hippocampus. $^{30}$ Likewise, other study reported that vitamin $\mathrm{D}_{3}$ enriched diet correlates with a decrease in the number of amyloid plaques and inflammation and increase in nerve growth factor in the brain of amyloidbeta protein precursor $(\mathrm{A} \beta \mathrm{PP})$ transgenic mice. ${ }^{31}$

Vitamin $\mathrm{D}_{3}$ had been related to up-regulation of the activity and expression of brain gamma glutamyl transpeptidase, a key enzyme involved in brain glutathione cycle, thus it ameliorates the antioxidant defence by increasing brain glutathione. ${ }^{32}$ Vitamin D improved the activity of glutathione in the cerebral cortex and striatum, and also increased glutamate cysteine ligase (GCLM), glutathione reductase, which improved glutathione synthesis and played an important role in anti-oxidation. ${ }^{33}$

Vitamin D supplementation in rats caused an increase in choline acetyl transferase activity (thus an increase in acetylcholine availability) in several specific brain areas. ${ }^{6}$ Also, calcitriol may enhance cholinergic function, both by increasing the activity of choline acetyl transferase (the key enzyme for acetylcholine synthesis) and by decreasing the activity of acetylcholine esterase (the enzyme that limits acetylcholine synapse transmission). ${ }^{34}$

An attenuation of cognitive deficits in the aged rats given vitamin $\mathrm{D}_{3}$ supplements compared to the aged control group when tested in the water maze. The two key findings are: decreased mean swim latency and path taken to reach the goal in the aged vitamin $\mathrm{D}_{3}$ group when compared to the aged control group; and increased memory recall during the probe trial in the aged rats given vitamin $\mathrm{D}_{3}$ in comparison to the aged control animals. $^{30}$

Folic acid significantly improved the levels of NMDA mRNA in the frontal cortexthe NMDA receptor, causes the nonselective cation channel to open, resulting in an inflow of calcium and sodium and an outflow of potassium. Intracellular calcium ions can be used as second messengers to participate in multiple signal transduction pathways to produce various effects, such as the activation of BDNF transcription, promotion of BDNF synthesis and increased levels of Trk B on the cell surface. ${ }^{35}$ Administration of folic acid prevent memory deficit and the reduction in BDNF levels induced by homocysteine injection. ${ }^{36}$ Folic acid supplementation converting homocysteine into cysteine can increase level of reduced glutathione in all the regions of brain. Also, this has beneficial effects in increasing the superoxide dismutase and catalase activities that are protective enzymes against highly reactive free radicals in the brain. $^{12}$
Other studies reported that impaired capacity of the folate-deficient rats to retain the task and escape from the maze by locating the escape platform. ${ }^{37}$ Folic acid $(8 \mathrm{mg} / \mathrm{kg})$ may potentiate the effect of memantine $(30 \mathrm{mg} / \mathrm{kg})$ on spatial learning and neuronal protection with significantly shorter of escape latencies in the MWM. The benefit of combination therapy may be through co-action on the methylation-controlled A beta production, and modification of brain gene expression. ${ }^{38}$

Memantine at a clinically relevant dose that renders the drug devoid of many of the side effects associated with high affinity NMDA channel blockers markedly increased the neurotrophin mRNA levels in different brain regions. Interestingly, memantine was able to enhance also the expression of the BDNF receptor, trk B, thus influencing the whole machinery responsible for BDNF signal propagation and increase the endogenous production of BDNF in the brain. ${ }^{39}$ Memantine is able to reduce apoptotic $A \beta$-induced effects, by reducing caspase- 3 and B-cell lymphoma 2 (Bcl-2) activation. ${ }^{40}$

Memantine, a low to moderate affinity noncompetitive NMDA receptor antagonist, can partially protect cultured neurons against A $\beta$-toxicity by attenuating phosphorylation of tau protein by reversing activation of multiple kinases including extracellular signal regulated kinases (ERK1/2) and glycogen synthase kinase 3 (GSK$3 \beta)$ and associated signaling mechanisms. ${ }^{41}$ Memantine may function not only as an antagonist of NMDA receptors, but also as an inhibitor of a novel translation initiation mechanism, the internal ribosome entry site (IRES), soblocking the expression of APP and tau protein and thereby relieving the symptoms of AD. ${ }^{16}$

Memantine provides beneficial effects in patients with $\mathrm{AD}$ by protecting the cholinergic neurons of excitotoxic destruction. ${ }^{42}$ Down-regulation of acetylcholine (Ach) production leads to an increase of inflammation and an appearance of AA by means of up-regulation of $\mathrm{N}$ methyl-D-aspartate (NMDA), and that serum anticholinergic activity (SAA) might be a biological marker of rapid progress of AD. ${ }^{43}$ Therefore, we considered that memantine, an antidementia agent, using the mechanism of antagonizing the NMDA receptor, abolished $\mathrm{AA}$ in $\mathrm{AD}$ patients at moderate stage. Memantine is able to enhance extracellular levels of ACh in the hippocampus, a brain structure highly relevant for declarative memory and Alzheimer's disease, and thatthis mechanism involves enhanced Ach release. ${ }^{44}$ Rats treated with memantine after a bilateral intra-cerebroventricular infusion of okadaic acid (OA) showed improved performance on MWM. $^{45}$

\section{CONCLUSION}

Data obtained in the present study pointed out that treatment of experimentally induced alzheimer rats with folic acid or vitamin $\mathrm{D}_{3}$ or memantine separately or combined group (folic acid+vitamin $\mathrm{D}_{3}$ ) resulted in 
significant increase of brain tissue levels of BDNF, acetyl choline (Ach), glutathione reductase with significant reduction of amyloid peptide 1-42 level with significant decrease of IAL, first RL and second RL to reach the platform with improvement of histopathological changes occurred in the brain. But combined and memantinetreated groups resulted in more significant improvement than other treated groups.

\section{Funding: No funding sources}

Conflict of interest: None declared

Ethical approval: The study was approved by the Institutional Ethics Committee

\section{REFERENCES}

1. Anand R, Gill KD, Mahdi AA. Therapeutics of Alzheimer's disease: Past, present and future. Neuropharmacol. 2014;76:27-50.

2. Mayeux R1, Stern Y. Epidemiology of Alzheimer disease. Cold Spring Harb Perspect Med. 2012;2(8):45-9.

3. Querfurth HW, LaFerla FM. Alzheimer's disease biomarkers: more than molecular diagnostics. Drug Develop Res. 2013;74:92-111.

4. Anderson DC. Alzheimer's disease biomarkers: more than molecular diagnostics. Drug Develop Res. 2013; 74:92-111.

5. Galasko D, Montine TJ. Biomarkers of oxidative damage and inflammation in Alzheimer's disease. Biomark Med. 2010;4:27-36.

6. Annweiler $\mathrm{C}$, Beauchet $\mathrm{O}$. Vitamin dementia: randomized clinical trials should be the next step. Neuroepidemiol. 2013;37:249-58.

7. Chabas JF, Alluin O, Rao G. Vitamin D2 potentiates axon regeneration. $J$ Neurotrauma. 2008;25(10):1247-56.

8. Pludowski P, Holick MF, Pilz S. Vitamin D effects on musculoskeletal health, immunity, autoimmunity, cardiovascular disease, cancer, fertility, pregnancy, dementia and mortality-a review of recent evidence. Autoimmun Rev. 2013;12(10):976-89.

9. Eyles DW, Burne TH, McGrath JJ. Vitamin D, effects on brain development, adult brain function and the links between low levels of vitamin D and neuropsychiatric disease. Front Neuroendocrinol. 2013;34(1):47-64.

10. Fernandes DA, Eyles D, Féron F. Vitamin D, a neuro-immunomodulator: Implications for neurodegenerative and autoimmune diseases. Psychoneuroendocrinol. 2009;34:S265-277.

11. Weinstein SJ, Hartman TJ, Stolzenberg-Solomon R, Pietinen P, Barrett MJ, Taylor PR. Null association between prostate cancer and serum folate, vitamin $\mathrm{B}$ (6), vitamin B (12), and homocysteine. Cancer Epidemiol Biomarkers Prev. 2003;12:1271-2.

12. Singh R, Kanwar SS, Sood PK, Nehru B. Beneficial effects of folic acid on enhancement of memory and antioxidant status in aged rat brain. Cell Mol Neurobiol. 2011;31:83-91.
13. Tsuneki H, Sekizaki N, Suzuki T, Kobayashi S, Wada T, Okamoto T, et al. Coenzyme Q10 prevents high glucose-induced oxidative stress in human umbilical vein endothelial cells. Eur J Pharmacology. 2007;566: 1-10.

14. Das UN. Folic acid and polyunsaturated fatty acids improve cognitive function and prevent depression, dementia, and Alzheimer's disease-But how and why? Prostaglandins Leukot Essent Fatty Acids. 2008;78:11-9.

15. Mattson MP. Pathways towards and away from Alzheimer'sdisease. Nature. 2004;430:631-9.

16. Wu TY, Chen CP. Dual action of memantine in Alzheimer disease: a hypothesis. Taiwan J Obstet Gynecol. 2009;48(3):273-7.

17. Saima K, Kaneez FS, Fatima, SK. Neuroprotective effect of curcumin and vitamin D3 on scopolamine hydro-bromide treated rat model of alzheimer's disease. EC Neurology. 2015;155-161.

18. Dehghani DHR, Reisi P, Azizi MHR, Alaei H, Pilehvarian AA. Effects of folic acid on passive avoidance learning and memory in rat alzheimer model by intracerebroventricular injection of streptozotocin. J Isfahan Med school. 2010;647-55.

19. Teresita LB, Darwish H. Vitamin D mitigates agerelated cognitive decline through the modulation of pro-inflammatory state and decrease in amyloid burden. J Neuroinflamm. 2012;9:244.

20. Catherine C, David FW, Joanne L, George, TT, John WO. Low Doses of Memantine Disrupt Memory in Adult Rats. J Neurosci. 2006;26(15):3923-32.

21. Aaro JJ, Katja AP, Jarkko IV, Veijo S, Anne M, Sirja $\mathrm{R}$, et al. Beneficial effect of prolyl oligopeptidase inhibition on spatial memory in young but not in old scopolamine-treated rats. Basic Clin Pharm Tox. 2007;100(2):132-8.

22. Gacar N, Mutlu O, Utkan T, Komsuoglu I, Gocmez SS, Ulak G. Beneficial effects of resveratrol on scopolamine but not mecamylamine induced memory impairment in the passive avoidance and Morris water maze tests in rats. Pharmacol, Biochem Behav. 2011;99(3):316-23.

23. Jamali-Raeufy N, Nasehi M, Ebrahimi-ghiri M, Zarrindast MR. Cross state-dependency of learning between WIN55, 212-2 and scopolamine in rat dorsal hippocampus. Neurosci Let. 2011;491(3):227-31.

24. Konar A, Shah N, Singh R, Saxena N, Kaul SC, Wadhwa R, Thakur MK. Protective role of ashwagandha leaf extract and its component withanone on scopolamine-induced changes in the brain and brain-derived cells. PloS one. 2011;6(11): e27265.

25. Aly HF, Metwally FM, Ahmed HH. Neuroptective effect of dehydroepiandrosterone (DHEA) in rat model of Alzheimer's disease. Acta Biochim Pol. 2011;58(4):513-20.

26. Kirk L, Ruchika S, Michelle W, Laura C, Suise H, MollyM, et al. Brain derived neurotrophic factor is associated with age-related decline in hippocampal volume. J Neurosci. 2010;30(15):5368-75. 
27. Sutherland MK, Somerville MJ, Yoong LK, Bergeron C, Haussler DR, McLachlan DR. Reduction of vitamin D hormone receptor mRNA levels in Alzheimer as compared to Huntington hippocampus: correlation with calbindin-28k mRNA levels. Brain Res Mol Brain Res. 1992;13:239-50.

28. Hanaa HA, Samiha MA, Fatma MA, Heba AM. Significance of vitamin $\mathrm{D}$ in combination with calcium in modulation of depression in the experimental model. Der Pharma Chemica. 2015;7(1): 128-47.

29. Shingo L, Sumio O, Yasuko N, Yusuke K, Sho M, Testsuya T. 1 1 25-dihydroxyvitamin D3 enhances cerebral clearance of human amyloid- $\beta$ peptide ( $1-$ 40) from mouse brain across the blood-brain barrier. Fluids Barriers CNS. 2011;8:20-9.

30. Briones TL, Darwish H. Vitamin D mitigates agerelated cognitive decline through the modulation of pro-inflammatory state and decrease in amyloid burden. J Neuroinflamm. 2012;9:24.

31. Yu J, Gattoni CM, Zhu H, Sambamurti K, Gattoni CS, Kindy MS. Vitamin D3 enriched diet correlates with a decrease of amyloid plaques in the brain of AbPP transgenic mice. J Alzheimers Dis. 2011;25(2):295-307.

32. Garcion E, Wion-Barbot N, Montero-Menei C, Berger F, Wion D. New clues about vitamin D in the nervous system. Trends Endocrinol Metab. 2002;13:100-5.

33. Jain SK, Micinski D. Vitamin D upregulates glutamate cysteine ligase and glutathione reductase, and GSH formation, and decreases ROS and MCP-1 and IL-8 secretion in high-glucose exposed U937 monocytes. Biochem Biophys Res Commun. 2013;437(1):7-11.

34. Humble MB. Vitamin D, light and mental health. J Photochem Photobiol. 2010;10:142-9.

35. West AE, Chen WG, Dalva MB, Dolmetsch RE, Kornhauser JM, Shaywitz AJ, et al. Calcium regulation of neuronal gene expression. Proceed Nat Acad Sci Am. 2001;11024-31.

36. MatteC, Pereira LO, Dos Santos TM, Mackedanz V, Cunha AA, Netto CA, et al. Acute homocysteine administration impairs memory consolidation on inhibitory avoidance task and decreases hippocampal brain-derived neurotrophic factor immunocontent: prevention by folic acid treatment. Neurosci. 2009;163(4):1039-45.

37. Troen AM, Chao WH, Crivello NA, D'Anci KE, Shukitt-Hale B, Smith DE, et al. Cognitive impairment in folate-deficient rats corresponds to depleted brain phosphatidylcholine and is prevented by dietary methionine without lowering plasma homocysteine. J Nutr. 2008;138(12):2502-9.

38. Chen TF, Huang RF, Lin SE, Lu JF, Tang MC, Chiu MJ. Folic Acid potentiates the effect of memantine on spatial learning and neuronal protection in an Alzheimer's disease transgenic model. J Alzheimers Dis. 2010;20(2):607-15.

39. Marvanová M, Lakso M, Pirhonen J, Nawa H, Wong $\mathrm{G}$, Castrén E. The neuroprotective agent memantine induces brain-derived neurotrophic factor and trkB receptor expression in rat brain. Mol Cell Neurosci. 2001;18(3):247-58.

40. Klyubin I, Wang Q, Reed MN. Protection against Abeta-mediated rapid disruption of synaptic plasticity and memory by memantine. Neurobiol Aging. 2011;32:614-23.

41. Floden AM, Li S, Combs CK. b-Amyloid-stimulated microgliainduce neuron death via synergistic stimulation of tumor necrosis factor aand NMDA receptors. J Neurosci. 2005;25:2566-75.

42. Ong KT. A $\beta$ imaging with $18 \mathrm{~F}$-florbetaben in prodromal Alzheimer;8's disease: a prospective outcome study. J Neurol Neurosurg Psychiatry. 2014; 86:431-6.

43. Hori K, Konishi K, Tomioka H, Tani M, Minegishi G, et al. Reviews: Serum anticholinergic activity: A biomarker for rapid progression of Alzheimer's disease. J Autacoids. 2012;4:1.

44. Ihalainen J, Sarajärvi T, Rasmusson D, Kemppainen S, Keski-Rahkonen P, Lehtonen M, et al. Effects of memantine and donepezil on cortical and hippocampal acetylcholine levels and object recognition memory in rats. Neuropharmacol. 2011;61(5-6):891-9.

45. Dashniani M, Chighladze M, Burjanadze M, Beselia G, Kruashvili L. Memantine attenuates the okadaic acid induced short-term spatial memory impairment and hippocampal cell loss in rats. Georgian Med News. 2016;(252):59-63.

Cite this article as: Eldeeb AA, Fathy AE, Elgendy SA. Differential potency of vitamin D3, folic acid and memantine in protecting against neurobehavioral alterations of scopolamine induced Alzheimer's model in rats. Int $\mathrm{J}$ Basic Clin Pharmacol 2021;10:471-8. 